\title{
Atividade Residual no Solo da Mistura Comercial dos Herbicidas Fluazifop-P-Butil e Fomesafen Utilizados no Cultivo Convencional e Direto do FeiJoeiro ${ }^{1}$
}

\author{
Soil Residual Activity of the Commercial Mixtures of the Herbicides Fluazifop-P-Butyl and \\ Fomesafen under Bean Tillage and No-Tillage Systems
}

JAKELAITIS, A. ${ }^{2}$, VIVIAN, R. ${ }^{3}$, SANTOS, J.B. ${ }^{4}$, SILVA, A.A. ${ }^{5}$ e SILVA, A.F. ${ }^{6}$

\begin{abstract}
RESUMO - Avaliou-se neste trabalho a atividade residual da mistura comercial dos herbicidas fluazifop-p-butil e fomesafen (Robust) em Argissolo Vermelho-Amarelo câmbico (PVAc), cultivado com feijão, nos sistemas de plantio direto e convencional. Cultivou-se, no sistema de plantio direto, o feijoeiro sobre as palhas de milho $\left(3,6 \mathrm{t} \mathrm{ha}^{-1}\right)$, Brachiaria brizantha $\left(15 \mathrm{t} \mathrm{ha}^{-1}\right)$ e milho + $B$. brizantha $\left(8,1 \mathrm{t} \mathrm{ha}^{-1}\right)$. No sistema convencional, o plantio do feijão foi realizado após a incorporação ao solo das palhas de milho $+B$. brizantha oriundas do consórcio. A mistura comercial dos herbicidas, na dose de $500 \mathrm{~mL} \mathrm{ha}^{-1}$, foi aplicada 30 dias após a emergência do feijão. Em amostras de solo coletadas aos 10, 29, 47, 72 e 119 dias após aplicação dos herbicidas (DAA), avaliou-se a persistência desses compostos no solo. Para isso, utilizou-se o método de bioensaio, tendo Sorghum vulgare como planta indicadora. Verificou-se que o PVAc apresentou elevada capacidade sortiva para a formulação comercial dos herbicidas. Independentemente do tipo e da quantidade de palha presente à superfície do solo no sistema de plantio direto, não se observou efeito residual dos herbicidas no solo a partir dos 10 DAA. Entretanto, quando a palha foi incorporada ao solo, no sistema convencional de cultivo, os sintomas de fitotoxidez e redução da altura e da massa seca da parte aérea de $S$. vulgare persistiram após 72 DAA dos herbicidas. A ausência dos sintomas de resíduos na planta indicadora, quando os herbicidas foram aplicados no sistema de plantio direto, pode ser atribuída, principalmente, à retenção desses produtos pela palha, impedindo o seu contato com o solo.
\end{abstract}

Palavras-chave: bioensaio, resíduos, sistemas de plantio, Phaseolus vulgaris.

\begin{abstract}
The residual activity of the commercial mixtures of the herbicides fluazifop-p-butyl and fomesafen was evaluated in Typic Hapludalfs soil in bean cultivated under tillage and notillage systems. The bean plant was cultivated under the tillage system over corn straw (3.6 tha ( $\left.^{-1}\right)$ Brachiaria brizantha (15 $\left.t h \mathrm{a}^{-1}\right)$ and corn straw + B. brizantha $\left(8.1 t h \mathrm{a}^{-1}\right)$. Under the tillage system, bean was planted after incorporation into the soil of the corn straws $+\boldsymbol{B}$. brizantha originating from the consortium. The commercial herbicide mixture (500 $\left.\mathrm{mL} \mathrm{ha}^{-1}\right)$ was applied 30 days after bean emergence. In soil samples collected at 10, 29, 47, 72 and 119 days after herbicide application (DAA), persistence was evaluated in the soil using the bioassay method and Sorghum vulgare as control. It was verified that Typic Hapludalfs soil has a high sorption capacity for fluazifop-p-butyl and fomesafen. Regardless of the type and amount of straw over the surface soil, under no tillage system, no herbicide residual effect on soil was verified after 10 DAA. However, when the straw was incorporated into the soil, under the tillage system, phytotoxicity symptoms, and reduced height and dry mass aerial part of S. vulgare persisted after 72 DAA of the herbicides. The absence of residual symptoms in the control plant, when the herbicides were applied under no tillage system, was attributed to straw retention, preventing its contact with the soil.
\end{abstract}

Keywords: bioassay, carryover, planting system, Phaseolus vulgaris.

Recebido para publicação em 9.2.2006 e na forma revisada em 4.8.2006.

2 Prof. Fundação Universidade Federal de Rondônia - UNIR, Campus Rolim de Moura, 78987-000 Rolim Moura-RO, <ajakelaitis@yahoo.com.br>. ${ }^{3}$ Doutorando em Fitotecnia, Escola Superior de Agricultura “Luiz de Queiroz" - ESALQ/USP. ${ }^{4}$ Pós-Doutorando em Fitotecnia, Departamento de Fitotecnia, Universidade Federal de Viçosa - DFT/UFV; ${ }^{5}$ Prof. Adjunto - DFT/ UFV; ${ }^{6}$ Mestrando em Fitotecnia, DFT/UFV. 


\section{INTRODUÇÃO}

Nas regiões tropicais, a sustentabilidade do sistema de plantio direto depende da palhada formada pela cobertura vegetal, que pode cobrir integralmente a superfície do solo e permanecer por longo período sobre este. Em ambientes em que ocorre rápida decomposição da palha à superfície do solo, recomenda-se o uso de resíduos de maior relação carbono/ nitrogênio, como aqueles provenientes de gramíneas (Calegari et al., 1993). Esse tipo de resíduo é produzido em sistemas consorciados de milho com forrageiras, que proporcionam excelente cobertura morta para o plantio direto de culturas subseqüentes, como o feijoeiro cultivado em sucessão a essas espécies (Silva et al., 2004).

A presença de palha no plantio direto, além de atuar como o principal fator de proteção do solo, contribui para a redução da infestação de plantas daninhas, em razão do impedimento físico e da produção de substâncias alelopáticas. Além desses benefícios proporcionados pelo sistema de plantio direto, Niekamp \& Johnson (2001) incluem outros, como o aumento da capacidade de retenção da água e a maior eficiência no uso de nutrientes. Entretanto, a presença de palha sobre o solo no plantio direto pode influenciar a eficiência de herbicidas de ação residual, principalmente aqueles aplicados em pré-emergência.

O processo de dissipação de herbicidas no ambiente está relacionado com as propriedades físico-químicas do herbicida e do solo, com as condições climáticas, com o manejo e com o sistema de cultivo utilizado (Clay, 1993; Niekamp \& Johnson, 2001). Na adoção dos sistemas convencional e direto de cultivo, a redistribuição dos herbicidas no solo pode ocorrer de forma diferenciada (Albuquerque et al., 2001). Além disso, os resíduos vegetais da cultura antecessora, existentes na superfície do solo no momento da aplicação do herbicida, podem impedir que este entre em contato direto com o solo. Ao ficarem retidos na palha, os herbicidas podem ser adsorvidos por esta, tendo como conseqüência a baixa lixiviação para o solo, mesmo após a ocorrência de chuvas (Rodrigues et al., 2000).

Entre os herbicidas atualmente utilizados na cultura do feijoeiro, a mistura comercial de fluazifop-p-butil + fomesafen (Robust) proporciona controle eficiente para a maioria das plantas daninhas mono e dicotiledôneas. Contudo, devido ao seu longo efeito residual no solo (Cobucci et al., 1998), o plantio posterior de culturas sensiveis, como o milho e o sorgo, necessita de intervalo mínimo de 150 dias após aplicação, podendo esse intervalo variar conforme o clima e a textura do solo (Rodrigues \& Almeida, 2005).

O objetivo deste trabalho foi avaliar os efeitos das palhas de milho, Brachiaria brizantha e milho $+B$. brizantha na atividade residual no solo da mistura comercial dos herbicidas fluazifop-p-butil + fomesafen, nos sistemas de plantio convencional e direto da cultura do feijoeiro.

\section{MATERIAL E MÉTODOS}

Este trabalho foi conduzido em um Argissolo Vermelho-Amarelo câmbico (PVAc), em Coimbra, MG, cuja análise química apresentou $\mathrm{pH}$ em água de 5,$5 ; \mathrm{H}+\mathrm{Al}^{+3}, \mathrm{Ca}$ e Mg de 5,01, 2,49 e 0,91 $\mathrm{cmol}_{\mathrm{c}} \mathrm{dm}^{-3}$, respectivamente; $\mathrm{P}$ e K de 19,55 e $87,50 \mathrm{mg} \mathrm{dm}^{-3}$; e 3,05 dag $\mathrm{kg}^{-1}$ de matéria orgânica. A composição textural foi de 23, 14, 14 e $49 \mathrm{dag} \mathrm{kg}^{-1}$ de areia grossa, areia fina, silte e argila, respectivamente.

As espécies antecessoras ao feijoeiro destinadas à formação de palha foram o milho (Zea mays) e o capim-marandu (Brachiaria brizantha). Elas foram semeadas no verão (novembro de 2003) e conduzidas em sistemas de monocultivo e de consórcio. A colheita do milho ocorreu na segunda quinzena de abril de 2004, e os resíduos vegetais permaneceram nas parcelas. Para obtenção da cobertura com palha de $B$. brizantha, a forrageira foi dessecada com glyphosate $\left(1,87 \mathrm{~kg} \mathrm{ha}^{-1}\right)$. A quantificação das palhas (t ha-1) de milho, B. brizantha e milho $+B$. brizantha, cultivados em consórcio, foi feita antes da semeadura do feijoeiro.

Para o plantio do feijão, utilizou-se a variedade BRSMG “Talismã”, pertencente ao grupo Carioca. No sistema convencional de plantio, foram realizadas uma aração e duas gradagens para uniformização do terreno, 15 dias antes da semeadura do feijoeiro. Utilizou-se para semeadura espaçamento de $0,45 \mathrm{~m}$, com 12 sementes por metro e adubação de plantio 
de $350 \mathrm{~kg} \mathrm{ha}^{-1}$ de 8-28-16 (N- $\left.\mathrm{P}_{2} \mathrm{O}_{5}-\mathrm{K}_{2} \mathrm{O}\right)$. Aos 25 dias após a emergência do feijoeiro, fezse a adubação com molibdênio na dose de $60 \mathrm{~g} \mathrm{ha}^{-1} \mathrm{e}$, no início do florescimento, a nitrogenada, aplicando-se o equivalente a $40 \mathrm{~kg} \mathrm{ha}^{-1}$ de $\mathrm{N}$ na forma de sulfato de amônio.

O delineamento utilizado foi o de blocos completos casualizados, com três repetições, arranjados em parcelas subdivididas. Os tratamentos (Tabela 1) foram alocados em parcelas de $153 \mathrm{~m}^{2}(9 \times 17 \mathrm{~m})$, e as subparcelas foram constituídas das épocas de coleta de solo para a avaliação dos resíduos $(10,29,47,72$ e 119 dias após aplicação dos herbicidas DAA). A mistura comercial dos herbicidas fluazifop-p-butil e fomesafen (Robust ${ }^{\circledR}$ ) foi aplicada na dose de $500 \mathrm{~mL} \mathrm{ha}^{-1}$, aos 30 dias após a emergência do feijoeiro, utilizando-se pulverizador costal calibrado para aplicação de $80 \mathrm{~L} \mathrm{ha}^{-1}$ de calda.

Para avaliação de resíduos da formulação comercial dos herbicidas fluazifop-p-butil e fomesafen, amostras de solo foram coletadas em quatro pontos na parcela, na profundidade de 0 a $10 \mathrm{~cm}$. Elas foram secas ao ar e à sombra, homogeneizadas e colocadas em vasos (120 g por vaso) em casa de vegetação, nos quais se semeou a espécie Sorghum vulgare como planta indicadora. Foram utilizadas cinco sementes por vaso, e, após a semeadura, o solo foi saturado com água e mantido próximo à capacidade de campo. Aos 21 dias após a semeadura, foram avaliadas a fitotoxidez (escala visual variando de 0 a 100 , em que 0 significa sem fitotoxidez e 100 representa a morte da planta indicadora), a altura e a massa seca da parte aérea das plantas de sorgo. Na detecção dos resíduos dos herbicidas no solo avaliado utilizaram-se curvas de dose-resposta previamente determinadas. Para isso, foi semeada a espécie indicadora (Sorghum vulgare) em vasos contendo $120 \mathrm{~g}$ do solo em estudo e de areia, isentos de herbicidas. Posteriormente, esses foram tratados com doses conhecidas da formulação comercial da mistura fluazifop-p-butil + fomesafen $(0 ; 0,47$; 0,$93 ; 1,87 ; 3,74 ; 7,48 ; 14,45 ; 29,92 ; 59,82$; 119,63 ; e $\left.329,26 \mathrm{~mL} \mathrm{ha}^{-1}\right)$ e $(0 ; 1,04 ; 2,08$; 4,$16 ; 8,32 ; 16,64 ; 33,27 ; 66,55 ; 133,10$; 266,19; e 532,38 $\mathrm{mL} \mathrm{ha}^{-1}$ ), em areia e solo, respectivamente. As curvas de dose-resposta para a mistura dos herbicidas fluazifop-p-butil e fomesafen foram expressas pelo modelo logístico $\hat{Y}$ a $/\left(1 \square(\mathrm{x} / \mathrm{b})^{\mathrm{c}}\right)$, em que "a" corresponde ao "nivel de saturação"; "b", ao $\mathrm{I}_{50}$; e "c", à declividade da curva em torno do $\mathrm{I}_{50}$ (Streibig, 1988; Souza et al., 2000).

As variáveis fitotoxidez, altura e massa seca da planta indicadora avaliadas na curva de dose-resposta foram submetidas à análise de regressão, determinando-se o $\mathrm{I}_{50}$ (concentração da mistura de herbicidas que inibe 50\% de resposta da planta em relação à testemunha sem herbicida) para ambos os substratos. Calculou-se também a relação de adsorção \{RA $=\left[\left(\mathrm{I}_{50}\right.\right.$ solo $-\mathrm{I}_{50}$ areia $) / \mathrm{I}_{50}$ areia $\left.]\right\}$, que expressa a capacidade sortiva do herbicida ao solo, tendo como parâmetros as concentrações do herbicida comercial em solo e areia que inibem 50\% do desenvolvimento da planta indicadora cultivada. Os resultados da atividade residual da formulação comercial dos herbicidas foram submetidos à ANOVA e, quando significativos,

Tabela 1 - Tratamentos utilizados para avaliação do efeito residual da formulação comercial dos herbicidas fomesafen e fluazifop-p-butil (Robust ${ }^{\circledR}$ ), aplicados em Argissolo Vermelho-Amarelo câmbico (PVAc), sob dois sistemas de cultivo do feijoeiro: convencional e direto

\begin{tabular}{|c|c|c|}
\hline Formação - palhada & Sistema de cultivo & Herbicida* \\
\hline Milho + Brachiaria brizantha $(8,1)$ & Plantio convencional & Testemunha sem herbicida \\
\hline Milho + Brachiaria brizantha $(8,1)$ & Plantio direto & Testemunha sem herbicida \\
\hline Milho + Brachiaria brizantha $(8,1)$ & Plantio convencional & Fomesafen + fluazifop-p-butil \\
\hline Milho + Brachiaria brizantha $(8,1)$ & Plantio direto & Fomesafen + fluazifop-p-butil \\
\hline Milho $(3,6)$ & Plantio direto & Fomesafen + fluazifop-p-butil \\
\hline Brachiaria brizantha $(15,0)$ & Plantio direto & Fomesafen + fluazifop-p-butil \\
\hline
\end{tabular}

* Aplicou-se a dose de $500 \mathrm{~mL} \mathrm{ha}^{-1}$ da formulação comercial Robust ${ }^{\circledR}$, aos 30 dias após a emergência do feijoeiro.

Valores entre parênteses representam toneladas ha ${ }^{-1}$ de palha.

Planta Daninha, Viçosa-MG, v. 24, n. 3, p. 533-540, 2006 
foram realizadas comparações de médias pelo teste de Tukey a $5 \%$ de probabilidade e análises de regressão.

\section{RESULTADOS E DISCUSSÃO}

As curvas de dose-resposta para solo e areia foram ajustadas pelo modelo logístico, observando-se aumento da fitotoxidez e redução da massa seca e altura das plantas indicadoras, com o aumento das doses da mistura comercial fluazifop-p-butil + fomesafen (Figura 1A, B). O ajuste do modelo às observações de fitotoxidez, massa seca e altura também satisfez o significado biológico esperado. Entretanto, observa-se grande diferença entre o $\mathrm{I}_{50}$ obtido no solo daquele em areia para todas as variáveis mensuradas. Em areia, $\mathrm{o}_{50}$ foi de $7,50,14,70$ e $4,49 \mathrm{~mL} \mathrm{ha}^{-1}$ de Robust $^{\circledR}$ para fitotoxidez, altura e massa seca das plantas de sorgo, enquanto em solo foi de 143,63, 196,08 e 137, $33 \mathrm{~mL} \mathrm{ha}^{-1}$ para as mesmas
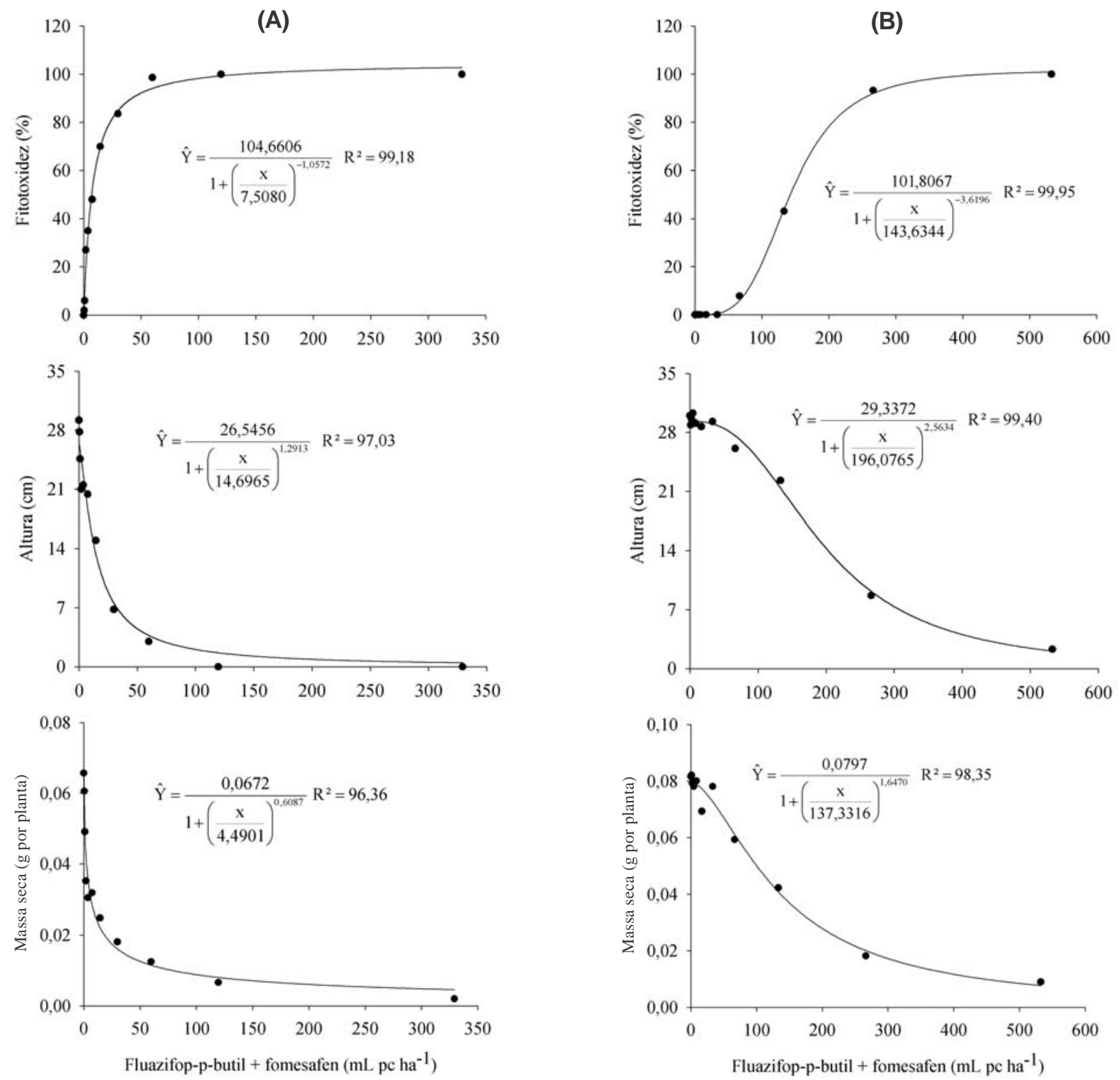

Figura 1 - Curva de dose-resposta para fitotoxidez, altura e massa seca da parte aérea de Sorghum vulgare em função de doses da mistura comercial dos herbicidas fluazifop-p-butil e fomesafen (Robust ${ }^{\circledR}$ ), aplicadas em areia (A) e em Argissolo Vermelho-Amarelo câmbico (PVAc) (B). 
variáveis avaliadas (Figura 1A, B). Assim, a relação de adsorção entre o $\mathrm{I}_{50}$ encontrado em solo e aquele na areia, considerada como substrato inerte, foi de 18,1, 12,3 e 29,6 para fitotoxidez, altura e massa seca das plantas, respectivamente. Essa relação representa a elevada capacidade sortiva dessa formulação comercial dos herbicidas fluazifop-p-butil e fomesafen no solo, a qual contribui para aumentar sua persistência no ambiente. Segundo Goetz et al. (1990), a adsorção das moléculas dos herbicidas aumenta a sua proteção da decomposição no solo, principalmente quando esta for de origem microbiana.

O conteúdo de carbono orgânico do solo é considerado fator primário que afeta a adsorção de herbicidas, sendo este altamente dependente da qualidade e da quantidade de matéria orgânica e argila do solo (Pusino et al., 2003). Dessa forma, a capacidade de adsorção do solo avaliado pode estar diretamente relacionada com a alta quantidade de matéria orgânica (3,05 dag $\mathrm{kg}^{-1}$ ) e de argila (49 dag $\mathrm{kg}^{-1}$ ) encontradas. Weber et al. (1993) e Guo et al. (2003) verificaram aumento na capacidade sortiva do herbicida fomesafen com a elevação da matéria orgânica e do $\mathrm{pH}$ dos solos avaliados. Em Argissolo Vermelho-Amarelo câmbico fase terraço com $42 \%$ de argila e $30,4 \mathrm{~g} \mathrm{~kg}^{-1}$ de carbono orgânico, Oliveira et al. (1998) também constataram elevada relação de adsorção $(25,5)$ desse solo em comparação à areia, no estudo de adsorção do herbicida flumioxazin, e que essa relação se deveu aos maiores teores de carbono orgânico, à argila e à presença de grande quantidade de agregados no solo.

Na Tabela 2, observa-se que para todos os sistemas culturais anteriormente utilizados no cultivo do feijão, com exceção do tratamento em plantio convencional, não foram detectados resíduos da mistura comercial dos herbicidas pela planta indicadora. Isso decorre da capacidade de retenção dos herbicidas no momento de sua aplicação sobre as palhas de milho e de B. brizantha. De acordo com Dao (1995) e Reddy et al. (1995), os resíduos vegetais possuem grande capacidade de sorção, às vezes superior à do solo; por conseguinte, o produto retido fica mais exposto às perdas por fotodecomposição, volatilização e/ou hidrólise provocada pela água da chuva. Observando a precipitação pluvial ocorrida durante o período avaliado (225 mm - Figura 3), parte do herbicida retido pode ter sido lixiviada para o solo, porém em quantidades insuficientes para que se manifestassem sintomas na planta indicadora. A capacidade adsortiva do PVAc, verificada pela relação de adsorção, também pode ter contribuído para a retenção dos herbicidas, sem que os sintomas fossem constatados na planta indicadora. Em sistema de plantio direto, também é possível que os herbicidas, ao atingirem o solo, tenham sido degradados mais rapidamente que no convencional. No sistema de plantio direto, em decorrência do não-revolvimento do solo e da manutenção deste coberto com palha, eleva-se a quantidade superficial de matéria orgânica e ocorre a redução das variações de amplitude de temperatura e umidade, o que aumenta, no ambiente edáfico, a diversidade, a atividade e biomassa microbiana, acentuando a degradação de herbicidas (Weed et al., 1995; Mueller et al., 1999). Cobucci et al. (1998) também verificaram que a maior umidade no solo reduziu a persistência do herbicida fomesafen em dois latossolos avaliados.

Quando o herbicida foi aplicado na área sob sistema convencional de cultivo, sem a presença de palha das espécies antecessoras sobre o solo, observaram-se fitotoxidez e reduções na massa seca e na altura da parte aérea da planta indicadora até os 72 dias após a aplicação dos herbicidas (Tabela 2, Figura 2). Neste mesmo tipo de solo, Fontes et al. (2004), avaliando a eficiência da pulverização e herbigação do fomesafen (225 $\left.\mathrm{g} \mathrm{ha}^{-1}\right)$ em plantios convencional e direto, verificaram atividade residual desse herbicida na profundidade de 0 a $10 \mathrm{~cm}$, até os 60 DAA, independentemente do sistema de cultivo utilizado. Para a mistura comercial fluazifop-p-butil + fomesafen, a alta persistência no solo é atribuída ao fomesafen, uma vez que o fluazifop-p-butil não apresenta mobilidade no solo e tem persistência média de 30 dias, enquanto o fomesafen apresenta meia-vida de 60 a 180 dias (Rodrigues \& Almeida, 2005).

Estudos realizados por Maciel \& Velini (2005) indicam que a quantidade de palha pouco interfere na transposição de herbicidas para a superfície do solo, de forma que a precipitação pluvial pode transportar facilmente o herbicida para o solo, quando não ocorrerem mecanismos específicos de retenção dos herbicidas. 
Tabela 2 - Fitotoxidez, altura e massa seca da parte aérea de Sorghum vulgare cultivado em amostras de solo (0-10 cm) coletadas em diferentes sistemas de cultivo do feijoeiro, aos 10, 29, 47, 72 e 111 dias após a aplicação da mistura comercial dos herbicidas fluazifop-p-butil e fomesafen (Robust ${ }^{\circledR}$ )

\begin{tabular}{|c|c|c|c|c|c|c|c|}
\hline \multirow{2}{*}{ Tratamento } & \multicolumn{5}{|c|}{ Dias após a aplicação dos herbicidas } & \multirow{2}{*}{ Equação de regressão } & \multirow{2}{*}{$\mathrm{r}^{2}$} \\
\hline & 10 & 29 & 47 & 72 & 111 & & \\
\hline \multicolumn{8}{|c|}{ Fitotoxidez (\%) } \\
\hline $\mathrm{PC}$, milho $+B$. brizantha testemunha & $0,00 \mathrm{~b}$ & $0,00 \mathrm{~b}$ & $0,00 \mathrm{~b}$ & $0,00 \mathrm{~b}$ & $0,00 \mathrm{a}$ & $\hat{\mathrm{Y}} \quad \overline{\mathrm{Y}} \quad 0$ & - \\
\hline PC, milho $+B$. brizantha tratado* & $92,61 \mathrm{a}$ & $76,53 \mathrm{a}$ & $82,53 \mathrm{a}$ & $25,67 \mathrm{a}$ & $0,50 \mathrm{a}$ & $\hat{Y} \quad 107,9485 \square 0,9736 X$ & 90,65 \\
\hline $\mathrm{PD}$, milho $+B$. brizantha testemunha & $0,00 \mathrm{~b}$ & $0,00 \mathrm{~b}$ & $0,00 \mathrm{~b}$ & $0,00 \mathrm{~b}$ & $0,00 \mathrm{a}$ & $\hat{\mathrm{Y}} \quad \overline{\mathrm{Y}} \quad 0$ & - \\
\hline PD, milho tratado* & $22,50 \mathrm{~b}$ & $1,77 \mathrm{~b}$ & $0,00 \mathrm{~b}$ & $1,87 \mathrm{~b}$ & $0,75 \mathrm{a}$ & $\hat{\mathrm{Y}} \quad \overline{\mathrm{Y}} \quad 5,38$ & - \\
\hline $\mathrm{PD}$, milho $+B$. brizantha tratado* & $2,78 \mathrm{~b}$ & $1,26 \mathrm{~b}$ & $0,06 \mathrm{~b}$ & $0,13 \mathrm{~b}$ & $0,00 \mathrm{a}$ & $\hat{\mathrm{Y}} \quad \overline{\mathrm{Y}} \quad 0,85$ & - \\
\hline PD, B. brizantha tratado* & $3,61 \mathrm{~b}$ & $1,83 \mathrm{~b}$ & $0,00 \mathrm{~b}$ & $0,67 \mathrm{~b}$ & $0,00 \mathrm{a}$ & $\hat{\mathrm{Y}} \quad \overline{\mathrm{Y}} \quad 1,22$ & - \\
\hline \multicolumn{8}{|c|}{ Altura $(\mathrm{cm})$} \\
\hline $\mathrm{PC}$, milho $+B$. brizantha testemunha & $27,19 \mathrm{a}$ & $26,87 \mathrm{a}$ & $28,07 \mathrm{a}$ & $29,07 \mathrm{ab}$ & $28,50 \mathrm{a}$ & $\hat{Y} \quad \bar{Y} \quad 27,94$ & - \\
\hline $\mathrm{PC}$, milho $+B$. brizantha tratado* & $3,56 \mathrm{~b}$ & $6,60 \mathrm{~b}$ & $9,53 \mathrm{~b}$ & $24,47 \mathrm{~b}$ & $28,91 \mathrm{a}$ & $\hat{\mathrm{Y}} \quad \square 0,3075 \square 0,2773 \mathrm{X}$ & 92,56 \\
\hline $\mathrm{PD}$, milho $+B$. brizantha testemunha & $26,56 \mathrm{a}$ & $28,69 \mathrm{a}$ & $29,80 \mathrm{a}$ & $31,60 \mathrm{a}$ & $29,16 \mathrm{a}$ & $\hat{Y} \quad \bar{Y} \quad 29,16$ & - \\
\hline PD, milho tratado* & $22,72 \mathrm{a}$ & $28,75 \mathrm{a}$ & $29,60 \mathrm{a}$ & $30,67 \mathrm{ab}$ & $27,93 \mathrm{a}$ & $\hat{\mathrm{Y}} \quad \overline{\mathrm{Y}} \quad 27,93$ & - \\
\hline PD, milho $+B$. brizantha tratado* & $26,72 \mathrm{a}$ & $27,07 \mathrm{a}$ & $31,00 \mathrm{a}$ & $29,27 \mathrm{ab}$ & $28,51 \mathrm{a}$ & $\hat{\mathrm{Y}} \quad \overline{\mathrm{Y}} \quad 28,51$ & - \\
\hline PD, B. brizantha tratado* & $27,30 \mathrm{a}$ & $27,62 \mathrm{a}$ & $29,93 \mathrm{a}$ & $28,07 \mathrm{ab}$ & $28,23 \mathrm{a}$ & $\hat{\mathrm{Y}} \quad \overline{\mathrm{Y}} \quad 28,23$ & - \\
\hline \multicolumn{8}{|c|}{ Massa seca da parte aérea (g por planta) } \\
\hline PC, milho $+B$. brizantha testemunha & $0,0788 \mathrm{a}$ & $0,0688 \mathrm{a}$ & $0,0746 \mathrm{a}$ & $0,0698 \mathrm{a}$ & $0,0691 \mathrm{a}$ & $\hat{Y} \quad \bar{Y} \quad 0,0722$ & - \\
\hline PC, milho $+B$. brizantha tratado* & $0,0225 \mathrm{~b}$ & $0,0304 \mathrm{~b}$ & $0,0336 \mathrm{~b}$ & $0,0502 \mathrm{a}$ & $0,0684 \mathrm{a}$ & $\hat{Y} \quad 0,0161 \square 0,0005 X$ & 98,25 \\
\hline $\mathrm{PD}$, milho $+B$. brizantha testemunha & $0,0862 \mathrm{a}$ & $0,0876 \mathrm{a}$ & $0,0831 \mathrm{a}$ & $0,0693 \mathrm{a}$ & $0,0827 \mathrm{a}$ & $\hat{Y} \quad \bar{Y} \quad 0,0818$ & - \\
\hline PD, milho tratado* & $0,0783 \mathrm{a}$ & $0,0913 \mathrm{a}$ & $0,0880 \mathrm{a}$ & $0,0615 \mathrm{a}$ & $0,0819 \mathrm{a}$ & $\hat{\mathrm{Y}} \quad \overline{\mathrm{Y}} \quad 0,0807$ & - \\
\hline PD, milho $+B$. brizantha tratado* & $0,0943 \mathrm{a}$ & $0,0859 \mathrm{a}$ & $0,0917 \mathrm{a}$ & $0,0750 \mathrm{a}$ & $0,0853 \mathrm{a}$ & $\hat{\mathrm{Y}} \quad \overline{\mathrm{Y}} \quad 0,0865$ & - \\
\hline PD, B. brizantha tratado* & $0,0921 \mathrm{a}$ & $0,0798 \mathrm{a}$ & $0,0792 \mathrm{a}$ & $0,0628 \mathrm{a}$ & $0,0786 \mathrm{a}$ & $\hat{\mathrm{Y}} \quad \overline{\mathrm{Y}} \quad 0,0845$ & - \\
\hline
\end{tabular}

$\mathrm{PC}$ - plantio convencional; PD - plantio direto; milho $\left(3,6 \mathrm{t}\right.$ palha ha $\left.{ }^{-1}\right)$; milho + B.brizantha $\left(8,1 \mathrm{t} \mathrm{ha}^{-1}\right) ;$ B.brizantha $\left(15,0 \mathrm{t}\right.$ ha $\left.{ }^{-1}\right) ; *$ tratamentos submetidos à dose de $500 \mathrm{~mL} \mathrm{ha}^{-1}$ de Robust ${ }^{\circledR}$ (mistura comercial dos herbicidas fluazifop-p-butil e fomesafen). Médias seguidas pelas mesmas letras, nas colunas, são estatisticamente iguais pelo teste de Tukey $(\mathrm{P}>0,05)$.

Embora se saiba que a interação herbicidasolo afeta a adsorção e, conseqüentemente, a persistência dos herbicidas no ambiente, o sistema de plantio direto reduz o contato do herbicida com o solo, além de contribuir para o aumento na atividade microbiológica deste. Dessa forma, a preservação da palha no solo atua como barreira física para o herbicida, impedindo que este alcance o solo e exerça seu efeito fitotóxico em culturas posteriormente instaladas. Todavia, constata-se a necessidade de novos estudos conduzidos sob o sistema direto de cultivo, a fim de verificar qual o intervalo necessário entre o uso desses herbicidas e o cultivo de culturas sensiveis de milho e sorgo, em diferentes condições edafoclimáticas, por ficar evidenciada a interferência dos sistemas de manejo sobre os efeitos dos herbicidas na cultura sucessora. 

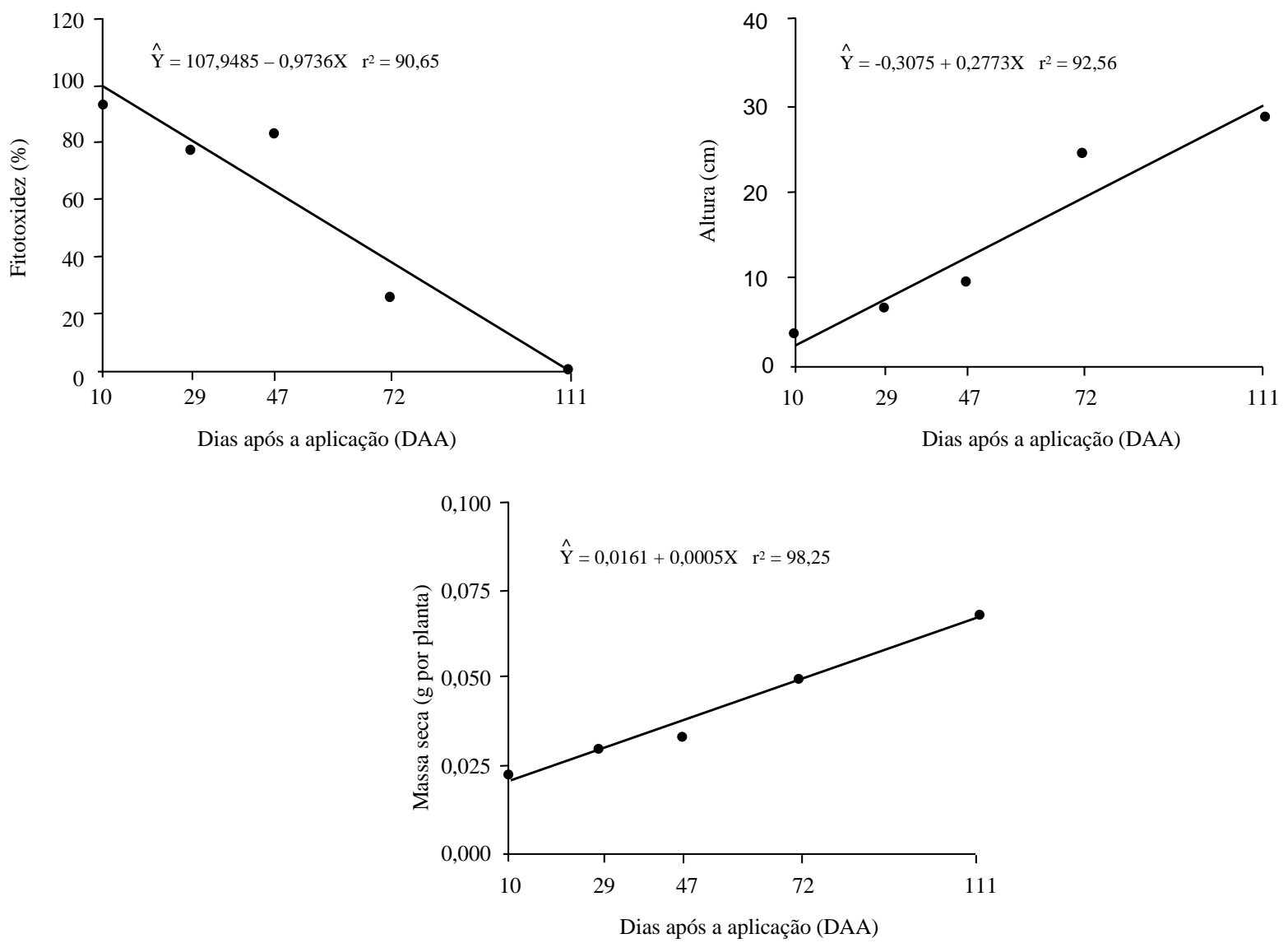

Figura 2 - Fitotoxidez, altura e massa seca da parte aérea de Sorghum vulgare cultivados em amostras de solo (0-10 cm) coletadas em sistema de plantio convencional, aos 10, 29, 47, 72 e 111 dias após a aplicação da formulação comercial dos herbicidas fluazifop-p-butil e fomesafen (Robust ${ }^{\circledR}$ ).

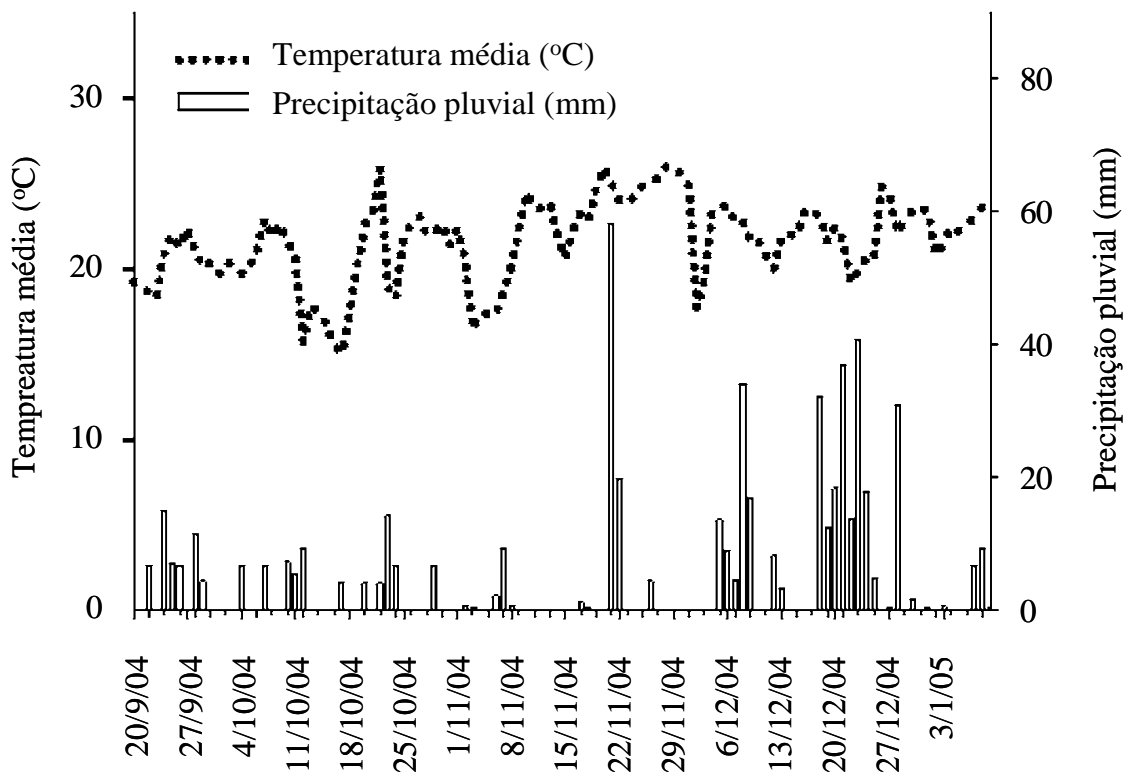

Figura 3 - Médias semanais de precipitação pluvial e temperatura média na área experimental, durante a condução do experimento. 


\section{LITERATURA CITADA}

ALBUQUERQUE, M. A. et al. Mineralização e sorção de atrazine em Latossolo Roxo sob cultivo convencional e direto. R. Bras. Ci. Solo, v. 25, n. 1, p. 179-188, 2001.

CALEGARI, A. et al. Aspectos gerais da adubação verde. In: COSTA, M. B. B. (Coord). Adubação verde no sul do Brasil. Rio de Janeiro: Assessoria e Serviços a Projetos em Agricultura Alternativa, 1993. p. 1-56.

CLAY, D. V. Herbicide residues in soils and plants and their bioassay. In: STREIBIG, J. C.; KUDSK, P. Herbicide bioassays. Florida: CRC Press, 1993. p. 153-172.

COBUCCI, T. et al. Effect of imazamox, fomesafen, and acifluorfen soil residue on rotational crops. Weed Sci., v. 46, n. 2, p. 258-263, 1998.

DAO, T. H. Subsurface mobility of metribuzin as affected by crop residue placement and tillage method. J. Environ. Quality, v. 24, n. 6, p. 1193-1198, 1995.

FONTES, J. R. A. et al. Lixiviação de herbicidas no solo aplicados com água de irrigação em plantio direto. Planta Daninha, v. 22, n. 4, p. 623-631, 2004.

GOETZ, A. J. et al. Degradation and field persistence of imazethapyr. Weed Sci., v. 38, n. 4/5, p. 421-428, 1990.

GUO, J. et al. Adsorption, desorption and mobility of fomesafen in Chinese soils. Water, Air, Pollut., n. 148, p. 77-85, 2003.

MACIEL, C. D. G.; VELINI, E. D. Simulação do caminhamento da água da chuva e herbicidas em palhadas utilizadas em sistemas de plantio direto. Planta Daninha, v. 23 , n. 3 , p. $471-481,2005$.

MUELLER, T. C.; SHAU, D. R.; WITT, W. W. Relative dissipation of acetochlor, alachlor, metolachlor and SAN 582 from three surface soils. Weed Technol., v. 13, n. 1, p. 341-346, 1999.
NIEKAMP, J. W.; JOHNSON, W. G. Weed management with sulfentrazone and flumioxazin in no-tillage soybean (Glycine max). Crop Protec., n. 20, p. 215-220, 2001.

OLIVEIRA, M. F. et al. Atividade dos herbicidas flumioxazin e metribuzin em diferentes solos. Planta Daninha, v. 16, n. 1, p. 37-43, 1998.

PUSINO, A. et al. Adsorption and desorption of triasulfuron by soil. J. Agric. Food Chem., v. 5, p. 5350-5354, 2003.

REDDY, K. N. et al. Chlorimuron ethyl sorption and desorption kinetics in soils and herbicide-desiccated cover crop 3. J. Agric. Food Chem., v. 43, n. 10, p. 2752-2757, 1995.

RODRIGUES, B. N.; ALMEIDA, F. R. Guia de herbicidas. 4.ed. Londrina: Edição dos Autores, 2005. 648 p.

RODRIGUES, B. N.; LIMA, J.; IADA, I. F. U. Retenção pela palhada de herbicidas aplicados em pré-emergência na cultura do milho, em plantio direto. R. Bras. Herbic., v. 1, n. 2, p. $67-72,2000$.

SILVA, A. A.; JAKELAITIS, A.; FERREIRA, L. R. Manejo de plantas daninhas no sistema integrado agriculturapecuária. In: ZAMBOLIM, L.; SILVA, A. A.; AGNES, E. L. Manejo integrado: integração agricultura-pecuária. Viçosa, MG: 2004. p. 117-169.

SOUZA, A. P. et al. Lixiviação do glyphosate e imazapyr em solos com diferentes texturas e composição mineral: Método do Bioensaio. Planta Daninha, v. 18, n. 1, p. 5-16, 2000.

STREIBIG, J. C. Herbicide bioassay. Weed Res., v. 28, n. 6, p. 479-484, 1988.

WEBER, J. B. et al. Mobility of fomesafen and atrazine in soil columns under saturated and unsaturated flow conditions. Pestic. Sci., v. 39, n. 1, p. 39-46, 1993.

WEED, D. A. J. et al. Dissipation and distribution of herbicides in the soil profile. J. Environ. Quality, v. 24, n. 1, p. 68-79, 1995. 